\title{
Progressive dialytic encephalopathy
}

\author{
S. CHOKR OVERTY ${ }^{1}, M$. E. B R UETMA N, V. BERGER, \\ A N D M. G. R E Y E S \\ From the Department of Neurology, Mount Sinai Hospital Medical Center, Chicago, \\ Neurology Service and Neurology Research Laboratory, Veterans Administration \\ Hospital, Hines, Illinois, USA
}

SYNOPSIS A subacutely progressive dialytic encephalopathy lasting for three to 15 months in 11 patients who had been on haemodialysis for 14 to 36 months was characterized by dementia, language disorder, myoclonic jerks, behavioural disturbance, distinctive EEG abnormalities, and normal or nonspecific neuropathological findings.

Since the introduction of successful extracorporeal dialysis by Kolf and Berk (1966) and maintenance haemodialysis by Scribner et al. (1960), the prognosis in terms of longevity for patients with the end stage renal failure has improved considerably. Parallel improvement after maintenance haemodialysis in metabolic derangements and the clinical manifestations has been gratifying for patients, who were destined to die within a short period of irreversible and inexorably progressive renal failure in the pre-dialysis era. However, it soon became apparent that long-term haemodialysis had its own hazards. Complications (Tyler, 1965; Hampers and Schupak, 1967; Talalla et al., 1970; Bluemle, 1971; Lindner et al., 1974) related to the technical aspects of dialysismetabolic bone disease, anaemia, haemosiderosis, pulmonary embolism, pericarditis, cardiomegaly, psychological problems, accelerated atherosclerosis, subdural haematoma, and peripheral neuropathy have all been known. Dialysis disequilibrium, reverse urea syndrome, water intoxication, seizures, myoclonus, and toxic psychosis have been frequently described as temporary complications of haemodialysis (Tyler, 1965; Hampers and Schupak, 1967). In some patients, prolonged confusional state may persist for days (Tyler, 1965) but eventually

\footnotetext{
1 Present address: P.O. Box 127, Hines, Illinois 60141, USA.

(Accepted 22 December 1975.)
}

the mental state reverts to the pre-dialytic stage. Furthermore, some patients in acute and terminal stage of chronic renal failure and immediately after dialysis (Tyler, 1965, 1968) develop confusion, disorientation, and convulsions progressing rapidly to coma and death. All these complications may be grouped under the general heading of acute dialytic encephalopathy (ADE). This paper directs attention to a less well-documented subacutely progressive dialytic encephalopathy (PDE) (Alfrey et al., 1972; Mahurkar et al., 1973; Burks et al., 1974; Chokroverty et al., 1974). A characteristic clinical picture accompanied by distinctive electroencephalographic (EEG) abnormalities emerged in 11 patients with chronic renal failure on long-term haemodialysis. Progressive dialytic encephalopathy in these patients, in contrast to patients with ADE or uraemic encephalopathy, did not depend either singly or in combination on rapid electrolyte shift, alteration of acid base balance, sudden rise of blood pressure, or increased levels of blood urea nitrogen or creatinine.

\section{REPORT OF CASES}

All patients had been on maintenance haemodialysis using Ex-03 coil or Dow hollow fibre dialyser three times a week for six hours each time. The dialysate was made up from commercial concentrate with non-ionizing tap water. 
CASE 1 A 55 year old woman with chronic glomerulonephritis had been on a long-term haemodialysis programme for 18 months. One month before admission she developed difficulty in speaking. Examination revealed an oriented woman with nonfluent speech; her comprehension was good but she had difficulty in finding the right words. Additionally, her speech was characterized by stuttering, mispronunciation, occasional anomia, agrammatism, and impairment of repetition. Her handwriting contained omissions and misspelling of the words. The rest of the physical examination was unremarkable. Her speech improved somewhat and she was discharged home five days later. She was readmitted five months after discharge with agitated delirium, visual and auditory hallucinations, and paranoid delusions. After treatment with sedation and tranquillizers, her agitation subsided. During the last two weeks of her life she developed intermittent myoclonic jerks bilaterally, continued to have paranoid delusions, and remained demented and dysphasic. She deteriorated progressively and died seven months after the onset of neurological disability.

CASE 2 A 47 year old woman had end stage renal disease due to hypertension. She had been on maintenance haemodialysis for 14 months. In August 1974 she developed myoclonic jerks in all four limbs intermittently. At about the same time she had several transient attacks of nonfluent dysphasia. In the course of the next three weeks her speech became normal, myoclonic jerks improved considerably, and she was discharged home. In October 1974 she was readmitted because of confusion, agitation, and inability to speak. Neurological examination revealed marked agitation, disorientation, and non-fluent dysphasia. Motor and sensory testing demonstrated normal findings and muscle stretch reflexes were symmetrically present. Her mental status and language problems showed day-to-day variation. On 6 November 1974 she suddenly had a cardiac arrest. Despite resuscitative measures she remained deeply comatose and died on 11 November 1974.

CASE 3 (Already published in detail by Mahurkar et al., 1973). Twenty-seven months after haemodialysis and bilateral nephrectomy, a 51 year old woman slowly became demented and later demonstrated grimacing, myoclonic jerks of limbs, dysphasia, and dyspraxia. She became progressively more demented and died three months after the onset of neurological dysfunction.
CASE 4 A 25 year old man was admitted on 8 July 1974 because of sudden onset of mutism and intermittent myoclonic jerks of face and limbs bilaterally for one week. He had been on a haemodialysis programme since July 1971 for chronic renal failure and hypertension. Examination revealed a cooperative man who was able to understand commands but was completely unable to talk. There was lingual dyspraxia. His handwriting, both spontaneously and while copying, displayed omissions, misspellings, and perseveration. The rest of the neurological examination was normal. In the course of the next 10 days his speech improved and he was discharged with a mild stuttering dysarthria. On 28 August 1974 he again became completely mute and again the speech improved in the course of the next 12 days. On 16 September 1974 he had a violent myoclonic jerk which caused him to fall. Since then he had been having intermittent myoclonic jerks of all four limbs. In January 1975, myoclonic jerks became more frequent and he was unable to talk, although he tried to open his mouth and was able to follow commands by mimicry. Two days latere his speech returned spontaneously, myoclonici jerks became less frequent, and he was discharged home. He was readmitted on 5 May 1975 because of progressively increasing dementia, myoclonic jerks, agitation, and delusions. On 16 May 1975 after a sudden episode of hypotension, he died.

CASE 5 A 46 year old man, who had long-term haemodialysis for chronic renal failure for 34 months, was admitted because of sudden inability to talk. In the course of the next three days his speech returned but he was noted to have nonfluent dysphasia. His writing displayed perseveration, omission, and misspelling of words. The language problem would show periodic exacerbation and remission. Three months after the onset of the neurological illness while having haemodialysis he had a transient episode of auditory hallucination. Seven months after the onset of his speech difficulties, he developed intermittent myoclonic jerks bilaterally which were made worse by noise. He became progressively demented and incontinent of urine and faeces. He would respond to loud noises, light flashes, and pinching by bilateral myoclonic jerks. He died six months after the onset of the neurological dysfunction.

CASE 6 A 43 year old woman had been on maintenance haemodialysis for hypertension, end stage kidney disease, and chronic renal insufficiency. She insidiously developed confusion, disorienta- 
tion, impairment of memory, and 'abnormal behaviour' while on chronic haemodialysis for 18 months. Her mental functions would fluctuate and on some days she showed remarkable improvement. However, in the course of the next three months she developed myoclonic jerks of all four limbs intermittently and apraxia of gait. She became progressively more demented and died six months after the onset of dementia.

CASE 7 Thirty-five months after long-term haemodialysis for chronic renal failure, a 44 year old woman developed myoclonic seizures. Pertinent neurological findings consisted of diffuse myoclonic jerks and left homonymous hemianopsia. Three months later she displayed intermittent confusion. Seven months after the onset of myoclonic seizures, she suddenly became mute. she was able to comprehend and follow commands but was unable to speak or write. Her mutism was gradually replaced by dysphasia which was characterized by inability to find the right words, hesitancy of speech, perseveration, and agrammatism. Subsequently, she developed 'bizarre' behaviour. She became agitated and pulled out her hair and eyebrows. Her mental functions progressively deteriorated and she died seven months after the onset of the myoclonic seizures.

CASE 8 After haemodialysis for 15 months for chronic renal failure, a 30 year old woman developed impairment of memory and bilateral myoclonic seizures. Two weeks later she began to act in a strange manner and displayed delusion of persecution, auditory hallucination, disorientation, and inappropriate affect. Her behaviour improved somewhat but she remained severely demented, continued to have intermittent bilateral myoclonic seizures, and died three months after the onset of the neurological illness.

CASE 9 A 46 year old man had been on long-term haemodialysis for three years for chronic glomerulonephritis and renal failure. A renal transplantation was unsuccessful because of rejection. He gradually developed impairment of memory, intermittent confusion, disorientation, hallucinations, delusions, and periodic attacks of 'bizarre' behaviour. Six to seven months after the onset of behavioural and memory disturbance he began intermittently to have frequent generalized tonicclonic seizures and bilateral myoclonic jerks. He later suddenly became dysphasic. He could comprehend well but was unable to read, write, or repeat words. His speech improved in the course of the next few days but his mental functions continued to deteriorate, myoclonic seizures became more frequent, and he died 15 months after the onset of dementia and 'bizarre' behaviour.

CASE 10 After haemodialysis for 15 months, a 43 year old woman presented with 'bizarre' behaviour, disorientation, impairment of memory, and paranoid delusions. She had had multiple hospital admissions for periodic exacerbations of agitated delirium, hallucinations, and paranoid delusions. Subsequently, she developed bilateral myoclonic seizures, dysphasia, and dyspraxia and died in status epilepticus three months after the onset of the neurological dysfunction.

CASE 11 A 40 year old woman had been on chronic haemodialysis for hypertension and renal failure since March 1971. In December 1973, during haemodialysis, she had a transient loss of consciousness and twitching of the mouth and had bitten her tongue. After this episode, her mental functions progressively became impaired. In March 1974, she was admitted in a mute state. She could not follow written commands, could not write, but was alert and able to mimic well. Additional pertinent neurological findings included foot grasp, snout reflex, and diminished ankle jerks bilaterally. While in the hospital she developed bilateral myoclonic jerks. Her spontaneous speech had returned one or two days after admission but her speech and writing were characterized by perseveration, hesitancy, misspelling, and omission of words. She also had right-left disorientation and dyscalculia. On the fourth hospital day she suddenly became very agitated and started shouting that someone was trying to kill her. Her paranoid delusions and agitation persisted and she suddenly died on the sixth hospital day.

LABORATORY DATA In nine patients the range of values for blood urea nitrogen, serum creatinine, sodium, potassium, calcium, phosphorus and albu$\mathrm{min}$, and blood $\mathrm{pH}$ during one year before the onset of PDE and during the period of neurological dysfunction did not show any significant overall changes. Except for slightly low protein in cases 5-7, the cerebrospinal fluid, examined in seven patients, was normal. Brain scan (cases 1, 2, 10), cisternal scan (cases $2,6,8,9$ ), cerebral angiogram (case 1) and pneumoencephalogram (case 9) gave normal results.

EEG STUDY Bipolar and referential recordings of the EEGs were obtained in all patients on an 8- 
or 16-channel electroencephalograph, using the International 10-20 electrode placement system. During some portion of the recording, EEG responses after clapping, pinching of the extremities, and eye opening and closing were noted. The EEG findings are summarized in Table 1. The dominant EEG rhythm consisted of 8-10 $\mathrm{Hz}$ activity in all except cases 5 and 7. An excessive amount of theta rhythm was present in six patients (cases 2, 4-8). All patients demonstrated bisynchronous, mostly anteriorly dominant, inter- mittent rhythmic delta waves in the majority of the tracings (Fig. 1). The second most common EEG manifestation was the presence of frontocentral spike-and-slow wave complexes in a bi-â laterally synchronous fashion (Fig. 2). These ${ }_{0}^{\top}$ epileptiform activities were present predominantly on the left side in case 5 , on the right in case $7, \frac{\overrightarrow{2}}{\underline{0}}$ and more or less symmetrically in the remaining cases. Photic stimulation (cases 3-6, 9, 11) acti- -

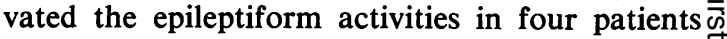
(cases 3-5, 9). Two patients (cases 2 and 5) demon-

T A B L E 1

EEG DATA IN PATIENTS WITH PROGRESSIVE DIALYTIC ENCEPHALOPATHY

\begin{tabular}{|c|c|c|c|c|c|}
\hline Case & $\begin{array}{c}\text { Dominant } \\
\text { rhythm } \\
(\mathrm{Hz})\end{array}$ & $\begin{array}{c}\text { Bisynchronous } \\
\text { rhythmic delta } \\
(\mathrm{Hz})\end{array}$ & $\begin{array}{c}\text { Frontocentral } \\
\text { spike-and-slow } \\
\text { waves }\end{array}$ & Sleep spindles & Other \\
\hline $\begin{array}{r}1 \\
2 \\
3 \\
4 \\
5 \\
6 \\
7 \\
8 \\
9 \\
10 \\
11\end{array}$ & $\begin{array}{l}9 \\
8-9 \\
8 \\
9-10 \\
7-8 \\
8 \\
7-8 \\
8 \\
9-10 \\
8 \\
9\end{array}$ & $\begin{array}{l}3 \\
2.5-3 \\
2-3 \\
3 \\
3 \\
2-3 \\
2.5-3 \\
2-3 \\
2-2.5 \\
2-3 \\
2-3\end{array}$ & $\begin{array}{l}\left\{\begin{array}{l}\text { Occasional } \\
\{\text { Frequent } \\
\text { None } \\
\text { Occasional } \\
\text { None }\end{array}\right. \\
\text { Frequent }\end{array}$ & $\begin{array}{l}\text { Symmetrical } \\
\text { No sleep } \\
\text { Symmetrical } \\
\text { No sleep } \\
\text { Symmetrical } \\
\text { No sleep } \\
\text { Symmetrical }\end{array}$ & $\begin{array}{l}\text { None } \\
\text { Excess 5-6 Hz. Triphasic waves } \\
\text { None } \\
\text { Excess 5-6 Hz } \\
\text { Excess 5-6 Hz. A few triphasic waves } \\
\text { Excess 5-7 Hz } \\
\text { Excess 5-6 Hz } \\
\text { Excess } 5 \mathrm{~Hz} \\
\text { None } \\
\text { Excess fast rhythms }\end{array}$ \\
\hline
\end{tabular}

(3-A1

P3-AI

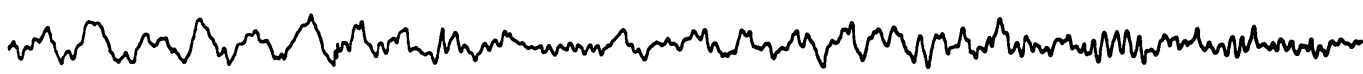

Or-AI

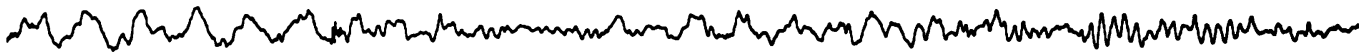

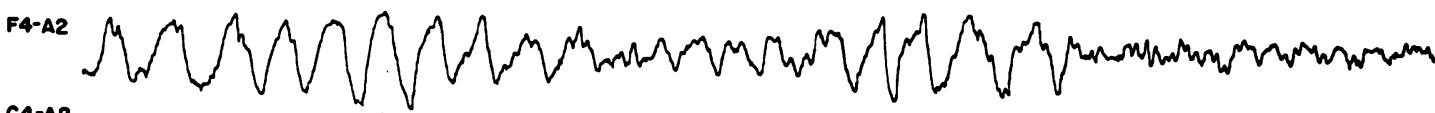
C4-A2

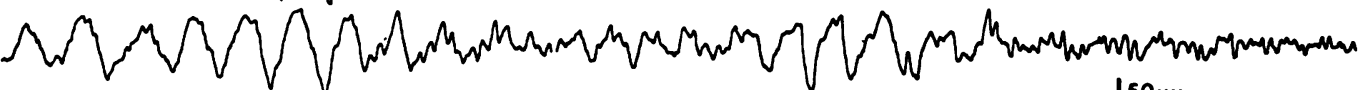
P4-A2

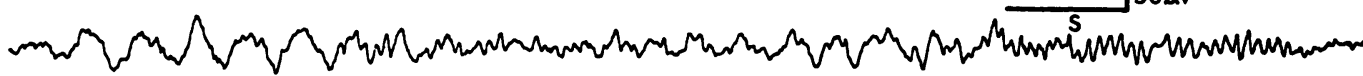

02-A2

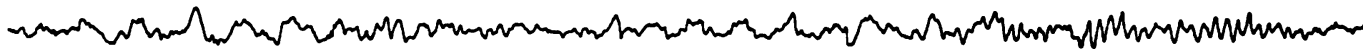
FIG. 1 Case 9. EEG. Bisynchronous anteriorly dominant intermittent rhythmic delta waves while awake. 
FPI-F 7

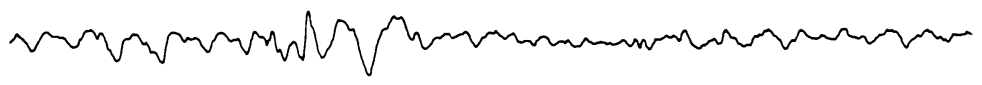

F7-T3 2007)

T3 - T 5 מnm

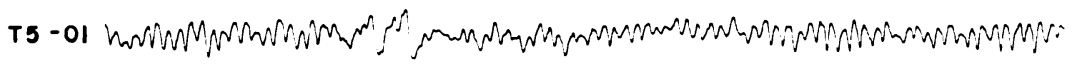

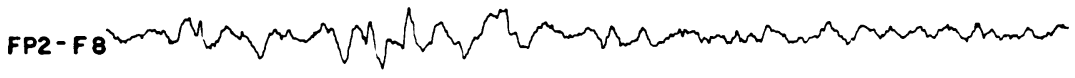

F8-T4 4)

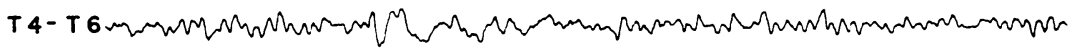

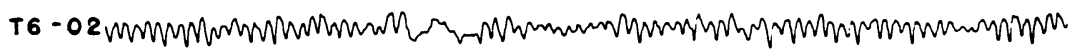

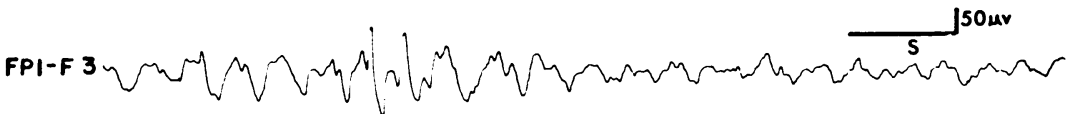

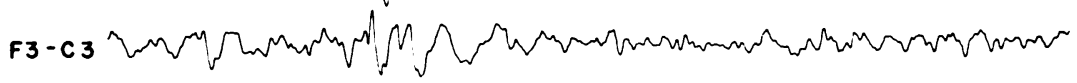

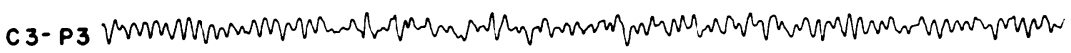

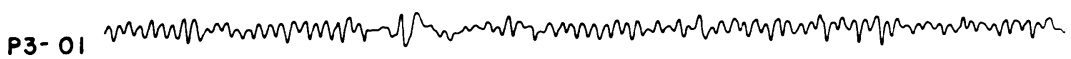

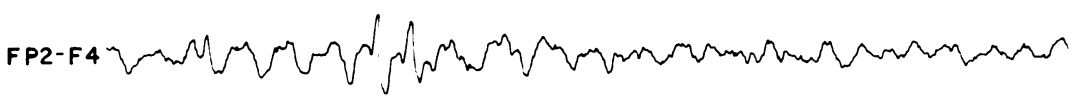

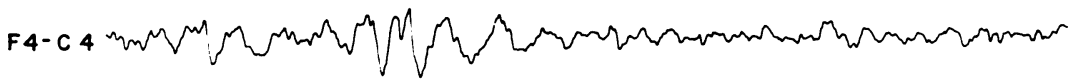

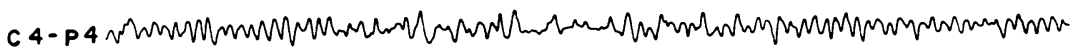

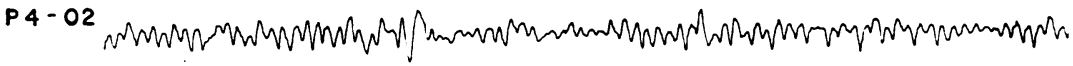

FIG 2 Case 9. EEG while awake. Frontocentral spike-and-slow waves and anteriorly dominant rhythmic delta waves seen bisynchronously.

strated triphasic waves during some part of the recording (Fig. 3). Pre-and post-dialysis EEGs did not show any significant variation in our patients.

PATHOlogical observations General postmortem examination performed in seven patients (cases 1-4, 9-11) showed left ventricular hypertrophy and congested liver in all patients. In cases $1,2,4$ and 11 there were bilateral contracted (end stage) kidneys. Case 3 had bilateral nephrectomy. In case 9 the left kidney was polycystic and the right kidney was absent (post-nephrectomy). Patient 10 had end stage left kidney and hypoplastic right kidney.

NEUROPATHOLOGICAL FINDINGS Neuropathological examination of the central nervous system in cases $1,4,9$, and 10 revealed normal findings. In case 2 , 


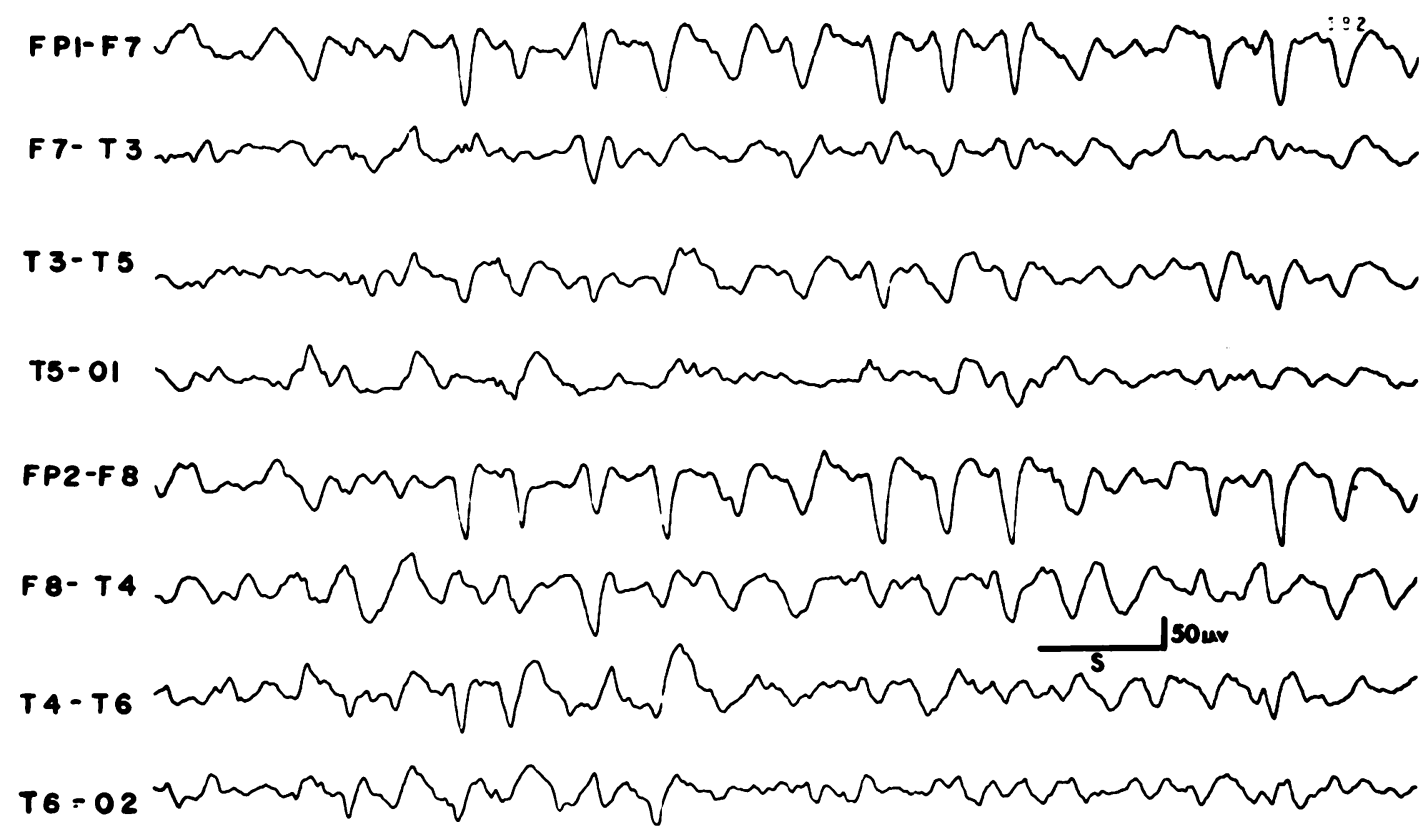

FIG. 3 Case 2. EEG. Anteriorly dominant bilateral triphasic waves.

multiple lacunae were noted bilaterally in the dorsomedial, ventral, and the right reticular nucleus of the thalamus, caudate nucleus, putamen, and the right insular cortex. In addition, there were anoxic-ischaemic changes in the cerebral, cerebellar, and subcortical neurones.

Macroscopic examination of the brain in case 3 was normal. Microscopically, there was an old lacunar infarction in the right putamen.

In case 11 , macroscopic examination of the brain was normal. Microscopically, there were lacunar infarcts bilaterally in the putamen and in the periaqueductal grey region of the midbrain.

\section{DISCUSSION}

CLINICAL ANALYSIS An analysis of the clinical features in these 11 patients revealed that the major manifestations of PDE can be grouped under four headings: (1) dementia; (2) language disorders; (3) myoclonic jerks, and (4) behavioural disturbances. These four features, the PDE tetrad, were present in seven patients (cases 1, 2, 4, 7, 9-11). Three manifestations of the tetrad were present in all patients, and therefore we believe that the term 'progressive dialytic encephalopathy' describes the entity more appropriately than the term 'dialysig dementia'. One notable feature was the perk. odic fluctuation but always inexorable pro के gression of the disease.

DEMENTIA This symptom was present in all patients. The main manifestations in these patients were confusion, disorientation, impairment of memory, and later behavioural disturbances. Progressive dialytic encephalopathy began with dementia in six patients (cases 3, 6, 8-11). Patient 4 developed dementia terminally.

LANGUAGE DISORDER This was characterized by mutism or global dysphasia with dominant difficulty in expression. Language dysfunction was the principal feature at the onset of PDE in four patients (cases 1, 2, 4, 5) and was present in course of the illness in all patients except in cases 6 and 8.

MYOCLONIC JERKS These were noted in all patients in the course of PDE and were the principal manifestations in the beginning of 
the illness in four patients (cases 2, 4, 7, 8). Myoclonic jerks were present bilaterally and sometimes were stimulus sensitive.

BEHAVIOURAL DISTURBANCES These symptoms were characterized by agitation, delirium, paranoid delusions, hallucinations, and sometimes by 'bizarre' behaviour. These were present in all patients and were the major manifestations at the onset of PDE in four patients (cases 6, 8-10).

In the initial period of our study (Chokroverty et al., 1974), it appeared that PDE probably progressed through three distinct stages. However, as more and more patients were observed over a period of time, we could not confirm our original impression as PDE manifested itself with the aforementioned tetrad in varying combination without passing through any distinct clinical stages. In our series, PDE began 14 to 36 months after maintenance haemodialysis and lasted from three to 15 months.

It is obvious from the above clinical analysis that any or all of the PDE tetrad may be present in uraemic encephalopathy in addition to focal sensory-motor deficits or seizures. However, there are distinct differences between the manifestations of PDE and uraemic encephalopathy and these are summarized in Table 2. According to Curtis et al. (1969), two to three periods of haemodialysis each week may not achieve the normal renal regulatory functions and, despite maintenance haemodialysis, these patients continue in a state of uraemia. Therefore, progressive dialytic encephalopathy would appear to be a variant of uraemic encephalopathy but with an altered course and related in some as yet unknown way to maintenance haemodialysis. Whether by increasing the frequency of dialysis the outcome of PDE could be altered or the patients became truly refractory to dialysis cannot be determined from our study. However, Burks et al. (1974) stated that more frequent dialysis did not alter the clinical course in their patients.

ELECTROENCEPHALOGRAPHY Normal or mildto-moderate slowing of the background EEG activity intermixed with frontally dominant intermittent rhythmic bisynchronous delta waves and frontocentral epileptic-type activities in patients with PDE were not specific but were characteristically noted in all patients during some stage of the illness. Similar EEG changes are known to occur in patients with uraemic or other metabolic encephalopathies (Cadilhac and Ribstein, 1961) and most probably indicate functional derangement of cortical and reticulocortical neurones. However, we did not observe appropriate anatomical alterations to account for dysfunction of cortical and reticulocortical neurones on neuropathological examination of the brain.

NEUROPATHOLOGICAL ASPECTS A survey of the literature reveals that the neuropathological changes in uraemic brain (Olsen, 1961) consist in variable combinations of neuronal degenera-

\section{T A B L E 2}

COMPARISON OF SALIENT FEATURES BETWEEN PROGRESSIVE DIALYTIC ENCEPHALOPATHY (PDE) AND URAEMIC ENCEPHALOPATHY

\begin{tabular}{|c|c|c|}
\hline Onset and relation to dialysis & $P D E$ after prolonged haemodialysis & $\begin{array}{l}\text { Uraemic encephalopathy after end stage } \\
\text { kidney disease. Improves after dialysis }\end{array}$ \\
\hline $\begin{array}{l}\text { Course } \\
\text { Duration of illness } \\
\text { Relation to systemic biochemical changes } \\
\text { Associated cerebrovascular disease } \\
\text { EEG }\end{array}$ & $\begin{array}{l}\text { Subacute } \\
3-15 \mathrm{~m} \\
\text { No definite relationship noted } \\
\text { None } \\
\text { Non-specific but distinctive (bisynchronous } \\
\text { rhythmic delta and frontocentral } \\
\text { spike-and-slow waves) }\end{array}$ & $\begin{array}{l}\text { Acute } \\
\text { Days to weeks } \\
\text { Usually related } \\
\text { Frequent } \\
\text { Non-specific and variable (diffuse and focal } \\
\text { slowing, spike-and-slow waves, } \\
\text { photosensitivity, and paradoxical alpha } \\
\text { attenuation) }\end{array}$ \\
\hline Neuropathological data & None significant. Sometimes lacunae in brain & $\begin{array}{l}\text { Variable combination of cerebral oedema, } \\
\text { infarction, and haemorrhage. Non-specific } \\
\text { loss of cortical and reticular neurones }\end{array}$ \\
\hline
\end{tabular}


tion, foci of softening, astrocytic proliferation, vascular damage, petechiae, focal demyelination, cerebral oedema, toxic encephalitis, and necrosis of the granular layer of the cerebellar cortex. We found none of these changes in our patients except lacunae in the basal ganglia and thalamus in cases 2,3 , and 11 . These lacunar infarcts cannot be responsible for the PDE tetrad and the EEG findings. Therefore, a marked disparity between the clinical and the neuropathological observations is very characteristic of the entity of PDE.

PATHOGENESIS Absence of morphological correlates for the clinical observations would tend to favour a possible metabolic cerebral dysfunction. However, as stated previously, there were no overall changes in the systemic biochemical parameters from the values noted before the onset of PDE. Therefore, it is problematical to ascribe the neurological illness to metabolic encephalopathy caused by altered systemic metabolism but there may be a possible relationship between PDE and uraemic encephalopathy as discussed above in the clinical analysis.

The group of investigators from Colorado (Alfrey et al., 1972; Burks et al., 1974) noted a high concentration of tin and decreased rubidium in the brains of seven patients with progressive dialytic encephalopathy. As there is no evidence of a significant role for rubidium in human health, these workers suggested tin as a possible aetiological factor in this type of encephalopathy. Although tin is known to cause an encephalopathy in animals and man (Torack et al., 1960; Alajouanine et al., 1958; Prull and Romple, 1970), the characteristic PDE tetrad, the distinctive EEG changes, absence of cerebral oedema (Torack et al., 1960) in our patients, the observations of high tin content in uraemic patients without encephalopathy (Alfrey et al., 1972), and the normal concentration of tin in the brain of at least one of our patients (Chokroverty et al., 1974) would speak against tin as an aetiological factor in PDE.

Finally, suggestion of possible dopamine (Wardle, 1973) or asparagine (Gunale, 1973) deficiency or any other cerebral neurochemical defect in PDE is pure speculation but may form a theoretical basis for a future line of investigation. At present, the aetiology of progressive dialytic encephalopathy remains unknown.

\section{REFERENCES}

Alajouanine, T. H., Dérobert, L., and Thiéffrey, S. (1958). Étude clinique d'ensemble de 210 cas d'intoxication par les sels organiques d'étain. Revue Neurologique, 98, 85-96.

Alfrey, A. C., Mishel, J. M., Burks, J., Contiguglia, S. R., Rudolph, H., Lewin, E., and Holmes, J. H. (1972). Syndrome of dyspraxia and multifocal seizures associated with chronic hemcdialysis. Transactions of the American Society of Artificial Internal Organs, 18, 257-261.

Bluemle, L. W., Jr (1971). Dialysis. In Diseases of the Kidney, vol 1, pp. 343-371. Edited by M. B. Strauss and L. G. Welt. Little, Brown: Boston.

Burks, J., Huddlestone, J., Lewin, E., Alfrey, A., c and Rudloph, H. (1974). A progressive encephalo ir pathy in chronic dialysis patients. (Read before the American Academy of Neurology, San Francisco 1974). Neurology (Minneap.), 24, 359.

Cadilhac, J., and Ribstein, M. (1961). The EEG ip metabolic disorders. World Neurology, 2, 296-308

Chokroverty, S., Bruetman, M. E., Berger, V. P Reyes, M. G., Meyers, H. L., Jr, and Smith. E. C: (1974). Progressive encephalopathy of chronie. hemodialysis. Transactions of the American Neurological Association, 99, 25-28.

Curtis, J. R., Eastwood, J. B., and Smith, E. K. M. (1969). Maintenance haemodialysis. Quarterly Journal of Medicine, 38, 49-89.

Gunale, S. R. (1973). Dialysis dementia: asparagine deficiency? Lancet (Letter to editor), $2,847$.

Hampers, C. L., and Schupak, E. (1967). Long-term Hemodialysis, pp. 119-133. Grune and Stratton: New York.

Kolf, W. J., and Berk, H. T. J. (1966). Artificial kidney: dialyser with great urea. Acta Medica Scandinavica, 117, 121-134.

Lindner, A., Charra, B., and Sherrard, D. (1974). Accelerated atherosclerosis in prolonged maintenance hemodialysis. New England Journal of Medicine, 290, 697-706.

Mahurkar, S. D., Dhar, S. K., Salta, R., Meyers, H. L., Jr, Smith, E. C., and Dunea, G. (1973). Dialysis dementia. Lancet, 1, 1412-1415.

Olsen, S. (1961). The brain in uremia. Acta Psychiatrica et Neurologica Scandinavica, suppl 156, 36, $1-128$.

Prull, G., and Romple, K. (1970). EEG Changes in acute poisoning with organic tin compounds. 
Electroencephalography and Clinical Neurophysiology, 29, 215.

Scribner, B. H., Buri, R., Caner, J. E., Hegstrom, R., and Burnell, J. M. (1960). The treatment of chronic uremia by means of intermittent hemodialysis: a preliminary report. Transactions of the American Society of Artificial Internal Organs, 6, 114-122.

Talalla, A., Holbrook, H., Barbour, B. H., and Kurze, T. (1970). Subdural hematoma associated with long-term hemodialysis for chronic renal disease. Journal of the American Medical Association, 212, 1847-1849.

Torack, R. M., Terry, R. D., and Zimmerman, H. M.
(1960). The fine structure of cerebral fluid accumulation. 2. Swelling produced by triethyl tin poisoning and its comparison with that in the human brain. American Journal of Pathology, 36, 273-287.

Tyler, H. R. (1965). Neurological complications of dialysis, transplantation and other forms of treatment in chronic uremia. Neurology (Minneap.), 15, 1081-1088.

Tyler, H. R. (1968). Neurological disorders in renal failure. American Journal of Medicine, 44, 734-747.

Wardle, E. N. (1973). Dialysis dementia. Lancet, (letter), 2, 47. 